\title{
Comparison of the VetGate and SurgiGATE 1.0 computer assisted surgery systems for insertion of cortex screws across the distal phalanx in horses - an in vitro study
}

\author{
Cornelia S. Schwarz', Tobias Rudolph², Jens H. Kowal² and Joerg A. Aver ${ }^{3}$ \\ 1 Kleintierklinik Klaus, Liestal, Switzerland \\ 2 ARTORG Center for Biomedical Engineering Research, University of Bern, Switzerland \\ ${ }^{3}$ Ammerwilerstrasse 5, Lenzburg, Switzerland
}

The study was conducted at the Equine Department, Vetsuisse-Faculty University of Zurich, Switzerland,

\begin{abstract}
Summary: The In vitro experimental study on five cadaveric equine limb pairs $(n=10)$ was conducted to evaluate the functionality and precision of the VetGate Computer Assisted Surgery (CAS) system during insertion of two $4.5 \mathrm{~mm}$ cortex screws across virtual midsagittal fractures of the distal phalanx (P3) in the horse and to compare the results with those achieved with the SurgiGate 1.0 CAS-System in a similar study. In each specimen wo $4.5 \mathrm{~mm}$ cortex screws were inserted computer assisted in lag fashion facilitated by the VetGate CASSystem. In none of the specimens did screw penetration of the articular- or solar surface or the semilunar canal, occur. The difference between optimal and actual screw length is significantly better in this study compared to a similar study conducted with the SurgiGATE 1.0 CAS-System. The results achieved with the VetGate CAS-System are even more precise than with the SurgiGATE 1.0 CAS-System $(p<0.001)$. The VetGate CAS-System allows exact screw placement at delicate locations.
\end{abstract}

Keywords - Computer-assisted surgery, distal phalanx fracture, osteosynthesis, screw placement, passive optic tracking system.

Citation: Schwarz C. S., Rudolph T., Kowal J. H., Auer J. A. (2017) Comparison of the VetGate and SurgiGATE 1.0 computer assisted surgery Systems for insertion of cortex screws across the distal phalanx in horses - an in vitro study. Pferdeheilkunde 33, 120-126; DOI 10.21836/PEM20170202

Correspondence: Prof. em. Joerg A. Auer, Dr Med Vet, Dr. h.c, Ammerwilerstrasse 5, 5600 Lenzburg, Switzerland; e-mail: jauer@swissonline.ch

\section{Introduction}

Computer assisted surgery (CAS) has been used in humans since the early 1990s for various orthopedic procedures (diGioia et al. 1998, Laine et al. 1997). CAS allows the surgeon to accurately implement the preoperative plan and to implant screws at the desired, preplanned location as well as at the correct (orthogonal) angle relative to the fracture plane (Aver 2003). The most popular application fields in humans are spine surgery, hip and knee arthroplasty and orthopedic trauma surgery of the pelvis. It could be shown in spine surgery that pedicle screws could be inserted with higher accuracy using image-guided computer navigation than with conventional methods (Laine et al. 2000). In total knee arthroplasty an improvement in both precision and accuracy in obtaining optimal knee alignment using CAS could be documented (Bathis et al. 2004, Sikorski and Blythe 2005).

Some studies reported on higher operation costs because of more expensive equipment and prolonged surgery time by equal or worse outcome than with conventional technique (Callaghan et al. 2006, Kim et al. 2009). Positive responses to this surgical adjunct promising further development and fine-tuning preponderate in the literature (Laine et al. 1997, Laine et al. 2000, Bathis et al. 2004, Sikorski and Blythe 2005, Chotanaphiti et al. 2008, Easley et al. 2008, Liebergall 2006).

Potential indications for CAS in equine surgery include fractures of the distal, middle and proximal phalanx, the distal and proximal sesamoid bones, and condylar fractures of $\mathrm{MCIII}$ and MTIII as well as subchondral cystic lesions of various bones (Fischer et al. 2006).

Two types of systems have been described: Active CASsystems, which work with infrared illuminating diodes that are connected via cables to a strober box, and passive systems, which recognize the bone and the instruments in the defined space via 3 to 4 reflecting marker balls mounted in different configurations on the $\mathrm{C}$-arm, the key instruments as well as the bone to be treated (Grützer et al. 2003).

Midsagittal fractures can be treated non-surgically or surgically. Internal fixation is recommended as treatment of choice (Fackelman 1974). Lag screw fixation provides temporary compression and stability and decreases the articular gap that persists with conservative therapy (Fackelman 2000). A prolonged convalescence in horses older than 3 years can be avoided by lag screw repair (Rose et al. 1979). Further immobilization to limit hoof expansion is recommended with a rimor bar shoe with side clips, usually leading to a contracted foot with associated problems and pain (Scott et al. 1979, Honnas et al. 1988). Potential complications include postoperative infection of the surgical site with development of osteomyelitis, screw irritation and screw rejection (Dyson 2003).

The partially encased joint within the hoof wall complicates the surgical access to the region preventing direct visualization of the bone or fracture during surgery. In conventional 
surgery the placement of a single screw across the fracture is relatively simple but requires fluoroscopic control or numerous intraoperative radiographs to determine the precise location of the screw position and to guide its placement (Young et al. 1995). The appropriate site for screw insertion is midway between the joint surface and the center of the semilunar canal. The desired direction of the screw is parallel to the joint surface and perpendicular to the fracture plane (Fackelman 1974, 2000, Honnas et al. 1992).

The results obtained with the SurgiGATE 1.0 System used in previous studies in distal virtual phalanx-and distal sesamoid bone fractures in the horse showed a greater precision of screw length selection and placement compared to the conventional technique (Andritzky et al. 2005).

The goal of this study was to determine the accuracy of the computer assisted (VetGate CAS-System) insertion of two cortex screws in lag fashion across a virtual midsagittal fracture of the distal phalanx. The results would be compared with those gained with the SurgiGATE 1.0 System (Andritzki et al. 2005, Gygax et al. 2006, Rossol et al. 2008).

\section{Materials and Methods}

\section{Cadaveric Limbs}

Five equine cadaveric limb pairs $(n=10)$ of horses culled for reasons other than musculoskeletal disease, collected at the Equine Hospital of the University of Zurich and the Equine Clinic Niederlenz, were used. The limbs were disarticulated at the carpometacarpal and the tarsometatarsal joint respectively. Because of the difficulties and inconsistencies in creating artificial fractures, a virtual midsagittal fracture was assumed for all samples.

\section{Technical Equipment}

The radiographic images were collected with the help of the isocentric C-arm Arcadis Orbic 3D (Siemens Healthcare, Erlangen, Germany). The object to be scanned is placed half way between the $x$-ray-emitting and the -receiving poles of the system, which reduces the size of the object that can be scanned. This 3-dimensional imaging system takes 100 high quality $2 \mathrm{D}$ radiographs over a $190^{\circ}$ orbital rotation within 60 seconds and calculates them into 256 separate slices that can be viewed in three orthogonal orientations (frontal-, sagittal-, and horizontal planes respectively) as well as a 3-D image. The data is then transferred to the VetGate System via a cable.

The VetGate CAS-System used in this study was a custommade (ARTORG Center for Biomedical Engineering Research, University of Bern, Bern, Switzerland). The system works with a passive, or indirect optic tracking system (Polaris Spectra, Northern Digital Inc., Waterloo, Ontario, Canada). The trakker (Fig. 1A) emits infrared light, which is reflected by retroreflecting marker balls connected to the bone (Fig. 2) to be treated and selected instruments used for screw insertion and picked up by two cameras (Fig. 1B) of the tracking system. At least three marker balls (BrainLab, Feldkrich, Germany) arranged in a unique configuration relative to each other (angle and distance) are attached to the objects to be navigated, such as hoof (Fig. 2), drill, drill sleeve, drill calibrator and C-arm. The SurgiGATE 1.0 worked with an active optic tracking system, where the instruments were tracked with infrared light emitting diodes. The drill sleeve was not navigated in this system (Andritzky et al. 2005, Gygax et al. 2006, Rossol et al. 2008). This system is not available anymore and the remaining one is not professionally serviced any more.

The room position of every marker can be identified relative to the camera. The planning and navigation software is based on the Open Source Framework MARVIN (Rudolph et al. 2008).

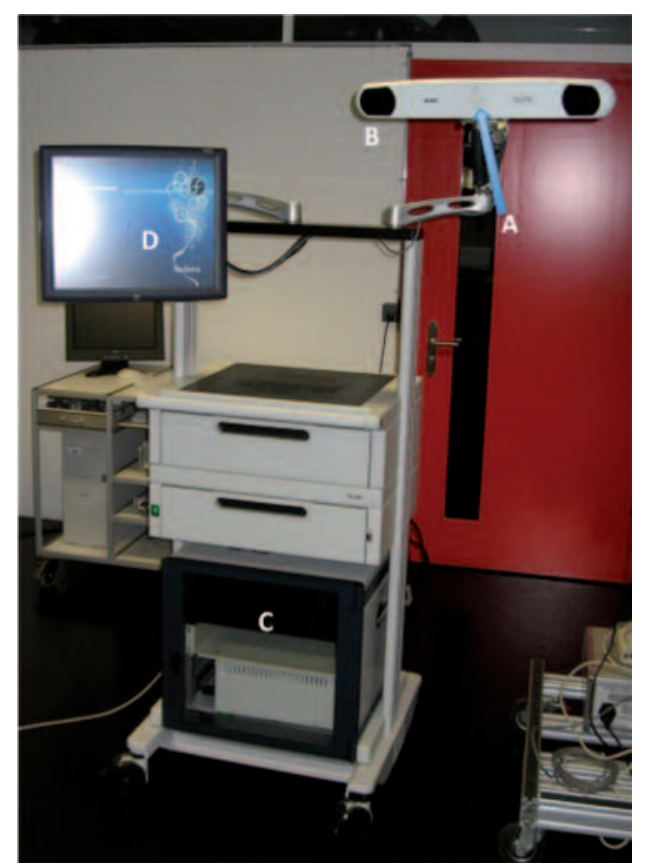

Fig. 1 The VetGate Tracker/camera system; A: infrared light emitting source; B: camera (there is another one on the other side of the horizontal beam); C: VetGate computer; D: screen.

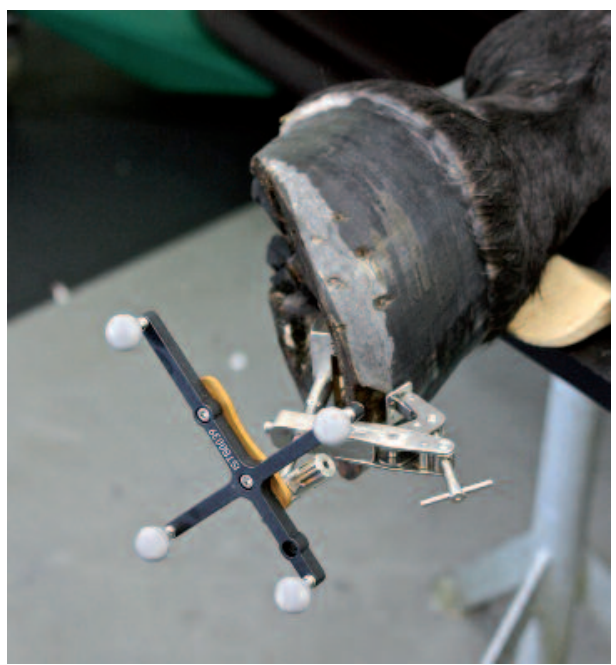

Fig. 2 Dynamic Reference Base (DRB) attached to the hoof tip showing the light reflecting balls at a specific configuration. The DRB used for the different instruments (drill guide, drill, calibration tool and bone) have different configurations of the reflecting balls for the computer to distinguish among them. 


\section{Surgical Procedure}

The frozen limbs were solidly fixed in lateral recumbency in a vice on an exchangeable carbon platform attached to the surgical table. The Dynamic Reference Base (DRB) with its marker-balls was attached with a specially designed clip (ARTORG Center for Biomedical Engineering Research, University of Bern, Bern, Switzerland) to the sagittal tip of the hoof capsule (Fig. 2). Two orthogonal fluoroscopic images were taken of the hoof-region to assure that the anatomic structures, such as distal phalanx were centered under the radiographic beam while the $\mathrm{C}$-arm rotated around the bone to be treated. The pertinent data of the patient, or in this case the sample number, were entered into the system followed by scanning of the hoof region (Fig. 3). The acquired data were screened on the monitor and subsequently transferred to the navigation computer, where the hoof structures could be observed in three planes.

In the planning mode of the navigation computer the distal phalanx was aligned such that the three orthogonal radiographic planes were oriented relative to midsagital axis of the limb. The screw diameter was determined; the screw axis was chosen orthogonal to the long axis of the limb and subsequently the screw drawn along this axis. Final adjustments

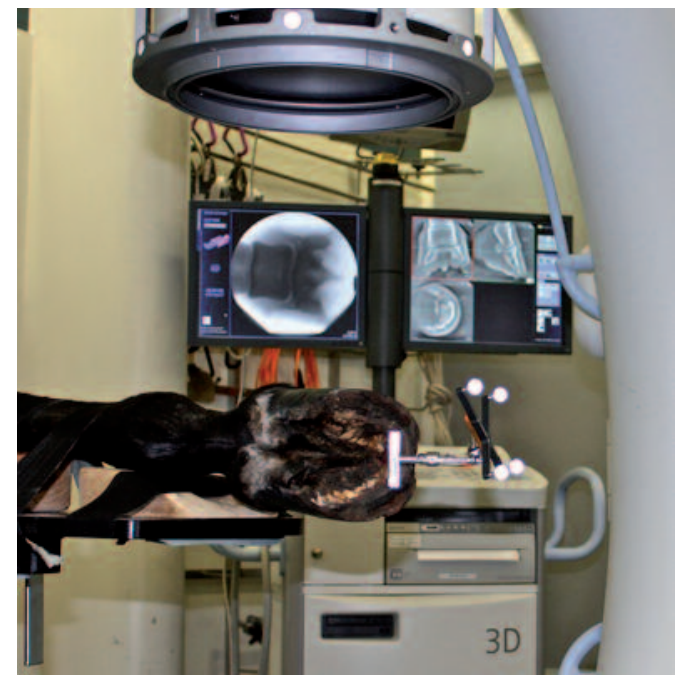

Fig. 3 X-Ray scan with the isocentric C-arm Arcadis Orbic 3D, also containing light-reflecting sensors.

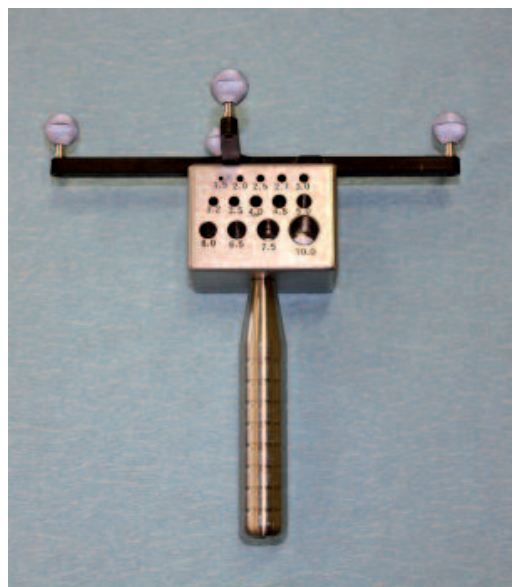

Fig. 4 Drill diameter and -length calibration-tool. were made in screw orientation and - length before the coordinates were identified and saved. In this manner, the desired number of screws - for the present study two $4.5 \mathrm{~mm}$ cortex screws - were pre-planned for every distal phalanx. The screw identification number, its diameter and length were depicted in a window at the left side on the computer screen. Potential interference of two preplanned screws could be observed on the monitor and if needed adjusted.

Once all screws were pre-planned and saved, the CASSystem was set to the navigation mode. The $4.5 \mathrm{~mm}$ drill bit was attached to the power drill and its diameter and length verified with the help of the drill calibrator (ARTORG Center for Biomedical Engineering Research, University of Bern, Bern, Switzerland) (Figs. 4 and 5). Because the drill bit itself has no attached markers this step is essential for the computer to know the exact length of the drill and with that the localization of the tip. The entry point and the drill bit direction were identified on the navigation screen and the glide hole for the screw prepared across the hoof wall (Fig. 6) under constant surveillance and adjustment of the drill bit angles in two orthogonal planes on the computer screen. Once the drill bit reached the bone surface, it was withdrawn, cleaned antthe glide hole rinsed. The glide hole was subsequently continued with the same diameter drill bit to and minimally crossing the midsagittal

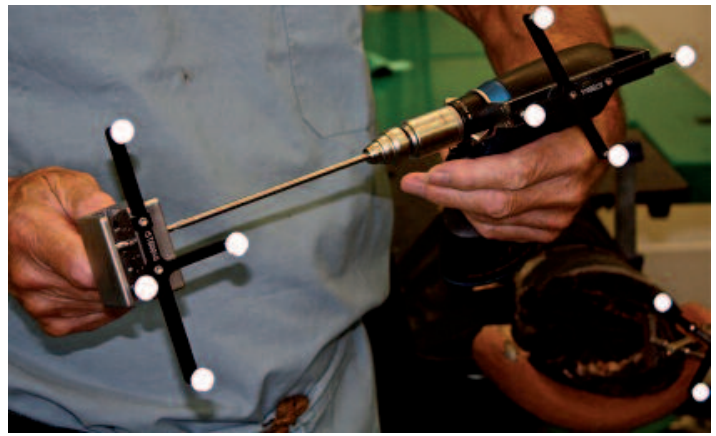

Fig. 5 Drill diameter and -length calibration. Both, the DRB on the drill and the on on the drill diameter and -length calibration-tool must be positioned such that the camera can identify them.

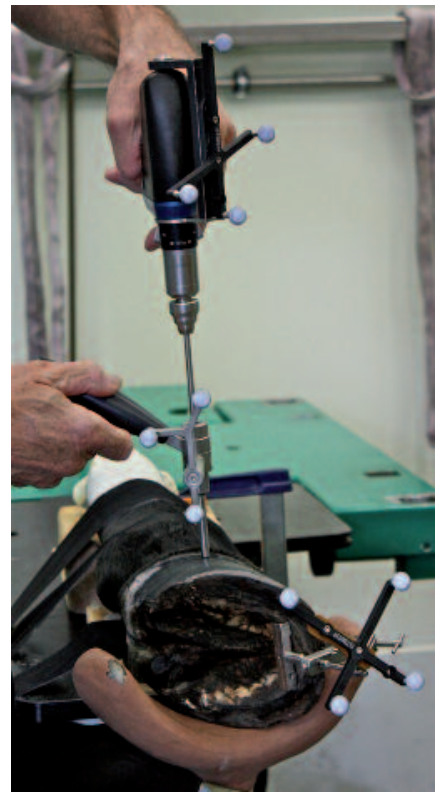

Fig. 6 The gliding hole is being prepared. Note, all the reflecting markers (Hoof wall, drill guide, and drill) have different configurations. 
plane (Fig. 7). The $4.5 \mathrm{~mm}$ drill bit was removed and exchanged with the $3.2 \mathrm{~mm}$ bit. After verification of the drill bit diameter and -length, the insert drill guide was placed into the glide hole and the thread hole was prepared across the remaining part of the distal phalanx. Once the drill bit reached the end of the bone, the exact screw length needed could be read off the navigation screen. The hole was subsequently tapped under navigation control to assure tapping of the entire thread hole without penetrating opposite hoof wall. The hoof wall hole was subsequently axially enlarged with a $10 \mathrm{~mm}$ diameter drill bit to facilitate countersinking the entry point of the screw into the bone and subsequent access of the screw head. A countersink depression was prepared manually to facilitate even distribution of the compressive forces around the perimeter of the screw-shaft junction.

The same procedure was repeated for the second screw hole. A screw length $2-3 \mathrm{~mm}$ shorter than the one determined during pre-planning was selected to account for the countersinking procedure. The selected cortex screw was inserted and solidly tightened. It should be noted that the depth gauge was not used to determine the length of the holes. Once selected, the screw was not changed anymore.

\section{Determination of the Screw Axis}

After preplanning was completed a virtual axis was drawn along the screw hole. The entry- and exit points of the bone were marked, followed by taking screens shot of the computer screen. The coordinates of the virtual axis were calculated by the VetGate computer program. The procedure was repeated along the screw following its insertion, again on the computer screen to allow comparison of the two axes.

Once the screw hole in the bone was completely finished immediately before screw insertion - 3-D imaging data acquisition with the Arcadis Orbic 3D was repeated to register the exact coordinates of the prepared hole-axes within the bone. These data were transferred again to the navigation system and in a later step the central longitudinal axes of the two holes were determined in the planning mode of the navigation system and the data stored for later comparison with the data recorded prior to the preparation of the actual screw holes.
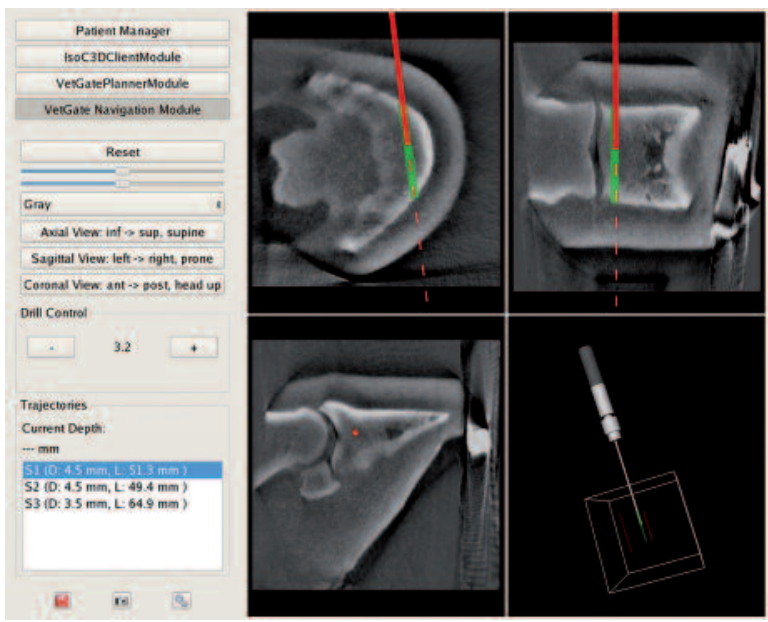

Fig. 7 Screen shot in "Navigation Mode" of the VetGate System during the drilling process of the gliding hole.
In an additional step the axes were also determined on preplanned screw holes and along the inserted screws from the records still available of the study by Andritzky et al. (2005).

\section{Macroscopic Evaluation}

All the bones were shelled out of their hoof capsule after soaking them twice for 4 hours in a 65 -degree water bath. To void the isolated distal phalanges off their soft tissue remnants, they were again boiled twice for 3 hours in a water bath. Once clean the articular- and solar surface of each bone was closely examined for accidental screw penetration and the entry- and exit points were evaluated for screw head seating and screw length respectively. The distance of the screw head and tip from the bone surface were measured with a sliding caliper. Screws being within $\pm 2 \mathrm{~mm}$ in length at the tip were judged as being of correct length. Digital photographic images (Fig. 8) were taken from all bones from the top, the bottom and from both sides.

In a next step the screws were removed and with the help of a band saw the distal phalanges transected in three parasagittal planes to determine accidental penetration of the semilunar canal.

\section{Statistical Analyses}

The statistical analyses were performed by using commercial computer software (STATA). The pre-planned and actual screw axes and lengths in the present study and the difference between optimal and computer determined screw length were compared to the data compiled in the study conducted by Andritzky et al. (2005) with the SurgiGATE System. The Student unpaired t-test was used for comparison of these data. To compare the Clinical Screw Length Assessment with the ones determined by Andritzky et al. (2005) the Fisher's exact chi square-test was used. For all analyses, a $P$ value $<0.05$ was considered significant.

\section{Results}

In none of the specimens did screw penetration of the articuperfectlylar or solar surface or the semilunar canal occur. Four out of the 20 screws were judged to be too short. The most

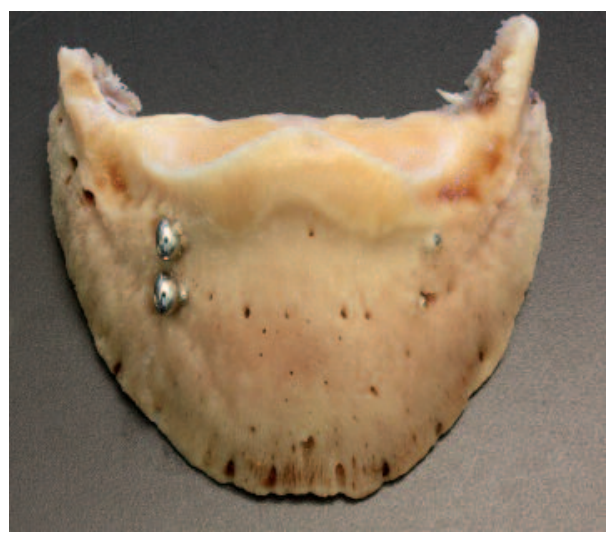

Fig. 8 Picture of the distal phalanx, extracted from the hoof capsule, showing the location of the two perfectly-placed cortex screws. 
Table 1 Difference between actual and computer-determined screw length in two different studies.

\begin{tabular}{ccc}
\hline Study & $\begin{array}{c}\text { Difference between } \\
\text { optimal and actual } \\
\text { screw length }\end{array}$ & $\begin{array}{c}\text { Difference between optimal } \\
\text { and computer determined } \\
\text { screw length }\end{array}$ \\
\hline VetGate & $1.40 \pm 1.47$ & $2.50 \pm 2.14$ \\
$\begin{array}{l}\text { SurgiGATE 1.0 } \\
\text { Andritzy et al. (2005) }\end{array}$ & $3.00 \pm 3.16$ & $2.82 \pm 2.27$ \\
$-\quad$ Comparison (Mean \pm SD in mm) of two Computer-Assisted Surgical Systems; \\
VetGate and SurgiGATE 1.0 CAS Systems; (Andritzky et al. 2005) for insertion \\
of 2 screws across a virtual midsagittal distal phalanx fracture.
\end{tabular}

\begin{tabular}{|c|c|c|c|}
\hline Table 2 & \multicolumn{3}{|c|}{ Comparison of clinical screw length assessment } \\
\hline Study & & Good \% (number) & Bad \% (number) \\
\hline VetGate & & $100(20)$ & $0(0)$ \\
\hline SurgiGATE & 1.0 Andritzky et al. 2005 & $93.7(15)$ & $6.3(1)$ \\
\hline
\end{tabular}

Screws were categorized as "good" (unlikely to cause pressure on the lamellae with the screw tip) or "poor" (likely to cause pressure on the lamellae). Protrusion of the screw head was not evaluated because it is never completely buried in the bone.

proximal aspect of one screw head was close to the distal interphalangeal joint surface but without penetrating it.

\section{Comparison of the Screw Axis}

For the data of the 20 screws, a mean discrepancy of axis angulation between pre-planning and the actual hole of $1.93^{\circ}$ (range, $0.25-4.04^{\circ}$ ) was determined. Mean difference in screw entry point was $2.45 \mathrm{~mm}$ (range, $0.85-4.18 \mathrm{~mm}$ ). The screw exit point had a mean difference of $3.02 \mathrm{~mm}$ (range, $1.26-5.41 \mathrm{~mm})$.

For the 10 proximal screws (S1): a mean discrepancy of angulation angle of: $1.93^{\circ}$ (range, $0.25-3.36^{\circ}$ ) was calculated. Mean difference in screw entry point was $2.27 \mathrm{~mm}$ (range, $0.85-4.18 \mathrm{~mm}$ ); screw exit point $3.32 \mathrm{~mm}$ (range, $1.81-4.95 \mathrm{~mm})$.

For the 10 distal screws (S2) a mean discrepancy of angulation angle of $1.92^{\circ}$ (range, $0.81-4.04^{\circ}$ ) was calculated. Mean difference in screw entry point was $2.62 \mathrm{~mm}$ (range, 1.57-3.76), screw exit point $2.73 \mathrm{~mm}$ (range, $1.26-5.41 \mathrm{~mm})$.

The difference between pre-planned and actual screw length is significantly better in this study $(p<0.001)$. There is no difference between optimal and computer determined screw length comparing the two studies (VetGate vs. SurgiGATE systems) $(p=0.5117)$ (Tab. 1).

No statistical difference could be determined between this study (A) and the one by Andritzky et al. (2005) (B) (Tab. 2).

\section{Discussion}

The CAS systems were not identical; the SurgiGATE 1.0 system is a direct system using a strober box, whereas the Vet-
Gate system belongs to the indirect system group. The benefit of the indirect systems includes the presence of reflecting sensors on all instruments used during screw insertion, specifically the drill guide. In these surgical procedures relatively long drill bits are used and if by applying pressure to the drill during preparation of the screw hole, the drill can bend and deviate from the desired direction. The presence of reflecting sensors on the drill guide prevents these errors to a great deal resulting in increased accuracy of screw hole preparation and subsequent screw placement. This in part explains the recorded differences between the two studies.

Another aspect for the better results in the present study is the improvement of the surgery technique, which changes with the learning curve of the surgeon (in both studies the same person) was exposed to.

The results of this study compared to the ones of Andritzky et al. (2005) are similar. A satisfactory outcome was achieved with both systems. The difference between pre-planned and actual screw length is significantly better in the present study. But the error rate is high using a sliding caliper. In this regard no difference was made between "too long" and "too short" because the importance was placed on trying to achieve a zero difference. In the clinical situation it is obvious the it is much better to have screw that is slightly shorter than to long because of the potential harming effects on the laminae of hoof wall.

Special emphasis was placed on the screw tip and not on the screw head. The countersinking of the screw head is a difficult aspect to evaluate and has only lately paid more tribute to (after completion of the study) in clinical cases. Excessive countersinking of the screw head may lead to inadequate compression force of the fracture plane because the screw is being "pulled" across the bone. No emphasis was placed on the parameter "surgery time", again the same surgeon was conducting all the procedures in both studies and therefore the present study benefitted from the learning curve experienced during the first study.

A total of 4 screws were determined as too short out of the 20 . The perfect screw length in this study was determined as follows: the tip should reach the bone surface $\pm 2 \mathrm{~mm}$. However in the clinical setting, the fixation of a fracture even with a slightly "too short" screws is adequate. The thread hole is between 20 and $30 \mathrm{~mm}$ long and provides adequate holding strength to solidly tighten a screw inserted in lag fashion. The missing $2 \mathrm{~mm}$ in a "too short" screw are therefore not significant. To avoid pressure on the sensitive laminae a short screw is preferred over a screw that is too long. Therefore these screws would be judged as perfect from a clinical point of view.

In a real case the total length of the hole is determined with the depth gauge after drilling and countersinking has been performed. This facilitates selection of a screw of correct length. Dependent upon the diameter of the hole in the hoof wall it may not be possible to insert the depth gauge all the way to the bone, resulting in an imprecise depth measurement. In most cases screws that are too long are selected. Such discrepancy can be detected after screw insertion by taking a tangential radiographic view at the screw exit point. If the screw protrudes after solid tightening, a shorter screw is 
selected. This could have been done in this experiment as well. However the decision was made at the onset of the study that we wanted to test the accuracy of the navigation system in determining the screw length needed. To compensate for the countersinking, 2-3 mm were deducted from the determined length. Also the screw lengths increase in $2 \mathrm{~mm}$ steps. Therefore, when an uneven length measurement was recorded, we deducted $3 \mathrm{~mm}$, with even recording we deducted $2 \mathrm{~mm}$.

In the study by Andritzky et al. (2005) $4 \mathrm{~mm}$ were deducted for the same reasons. In a in vitro study (non-published data because of too small a number of specimens) conducted on cadaveric limbs following the study of Andritzky et al. (2005) it was determined that $2-3 \mathrm{~mm}$ deduction was adequate.

In a real case, the first drill used has to be exchanged after penetration of the hoof capsule. This reduces the contamination risk of surgical the site by the drill bit, because the hoof capsule, even after meticulous aseptic preparation cannot be looked at as being sterile. We did not exchange the drill in this study, to save time and drill bits and mainly because we worked on cadaveric limbs.

\section{Acknowledgement}

The authors thank Mike Hässig for statistical analysis; Urs Müller, Kathrin Süss, Bruno Gretzner and Paul Müller for their invaluable support during collection, dissection and evaluation of the limbs.

\section{References}

Andritzky J., Rossol M., Lischer C., Auer J. A. (2005) Comparison of computer-assisted surgery with conventional technique for the treatment of axial distal phalanx fractures in horses: an in vitro study. Vet. Surg. 34, 120-127

Auer J. A. (2003) Computer assisted orthopedic surgery (CAOS) in equine fracture treatment. Proc. Europ. Coll. Vet. Surg. 12, 70

Bäthis H., Perlick L., Tingart M., Lüring C., Zurakowski D., Grifka J. (2004) Alignment in total knee arthroplasty. A comparison of computer-assisted surgery with the conventional technique. J. Bone Joint Surg. Br. 86, 682-687

Callaghan J. J., Liu S. S., Warth L. C. (2006) Computer-assisted surgery: a wine before its time: in the affirmative. J. Arthroplasty 21, $27-28$

Chotanaphuti T., Ongnamthip P., Teeraleekul K., Kraturerk C. (2008) Comparative study between computer assisted-navigation and conventional technique in minimally invasive surgery total knee arthroplasty, prospective control study. J. Med. Assoc. Thai. 91, 1382-1388.

DiGioia A. M., Jaramaz B., Colgan B. D. (1998) Computer assisted orthopedic surgery. Image guided and robotic assistive technologies. Clin. Orthop. 8-16

Dyson S. J. (2003) Fractures of the distal phalanx in Mike W. Ross, M. W., Dyson S. J. (Eds): Diagnosis and Management of Lameness in the horse. W. B. Saunders Company, St. Louis, Missouri, 318-321

Easley M., Chuckpaiwong B., Cooperman N., Schuh R., Ogut T., Le I. L. D., Reach J. (2008) Computer-assisted surgery for subtalar arthrodesis. A study in cadavers. J. Bone Joint Surg. Am. 90, 1628-1636

Fackelman G. E., von Salis B., Aver J. A. (1974) Screw Fixation of Sagittal Fractures of the third Phalanx in Horses. Vet. Med. Small Anim. Clin. 96,1317-1324

Fackelman G. E. (2000) Distal Phalanx. In Fackelman G. E., Auer J. A., Nunamaker D. M., (Eds): AO Principles of Equine Osteosynthesis. Stuttgart Thieme Verlag, 115-124
Fischer A. T., Hardy J., Léveillé R., Rijkenhuizen A. B. M., Aver J. A. (2006) Minimally Invasive Surgical Techniques. In: Auer J.A., Stick J.A. (Eds): Equine Surgery, third ed., Saunders Elsevier, St. Louis, Missouri, 161-172

Gebhard F., Arand M., Fleiter T., Hebecker A., Heeckt P., Hesser J., Messmer P., Hüfner T., Visarius H., Regazzoni P., Kinzl L. (2001) Computer assistierte Chirurgie, Entwicklung und Perspektiven 2001. Der Unfallchirurg 104, 782-788

Grützner P. A., Hebecker A., Wälti H., Vock B., Nolte L.-P., Wentzen$\operatorname{sen} A$. (2003) Klinische Studie zur registrierungsfreien 3D-Navigation mit dem mobilen C-Bogen SIREMOBIL Iso-C3D. Electromedica 71, 58-67

Gygax D., Lischer C., Auer J. A. (2006) Computer-assisted surgery for screw insertion into the distal sesamoid bone in horses: an in vitro study. Vet. Surg. 35, 626-633

Honnas C. M., O'Brien T. R., Linford R. L. (1988) Distal phalanx fractures in horses: A survey of 274 horses with radiographic assessment of healing in 36 horses. Vet. Radiol. 29, 98-107

Honnas C. M., Vacek Jr., Schumacher J. (1992) Diagnosis and treatment of articular fractures of the equine distal phalanx. Vet. Med. 87, 1208-1214

Kim Y.-H., Kim J.-S., Choi Y., Kwon O.-R. (2009) Computer-Assisted Surgical Navigation Does Not Improve the Alignment and Orientation of the Components in Total Knee Arthroplasty. J. Bone Joint Surg. Am. 91, 14-19

Laine T., Schlenzka D., Mäkitalo K., Tallroth K., Nolte L. P., Visarius $H$. (1997) Improved accuracy of pedicle screw insertion with computer-assisted surgery. A prospective clinical trial of 30 patients. Spine 22,1254-1258

Laine T., Lund T., Ylikoski M., Lohikoski J., Schlenzka D. (2000) Accuracy of pedicle screw insertion with and without computer assistance: a randomized controlled clinical study in 100 consecutive patients. Europ. Spine J. 9, 235-240

Liebergall M., Ben-David D., Weil Y., Peyser A., Mosheiff R. (2006) Computerized navigation for the internal fixation of femoral neck fractures. J. Bone Joint Surg. Am. 88:1748-1754

Rose R. J., Taylor B. J., Bellenger C. R. (1979) Internal fixation of fractures of the third phalanx in three horses. Aust. Vet. J. 55, 29 32

Rossol M., Gygax D., Andritzky-Waas J., Zheng G., Lischer C., Aver J. A. (2008) Comparison of computer assisted surgery with conventional technique for treatment of abaxial distal phalanx fractures in horses: an in vitro study. Vet. Surg. 37, 32-42

Rudolph T., Puls M., Anderegg C., Ebert L., Broehan M., Rudin A., Kowal J. (2008) MARVIN: a medical research application framework based on open source software. Comput. Meth. Prog. Biomed. 91, (2), 165-174

Scott E. A., McDole M., Shires M. H. (1979) A review of third phalanx fractures in the horse: sixty-five cases. J. Am. Vet. Med. Assoc. 174, 1337-1343

Sikorski J. M., Blythe M. C. (2005) Learning the vagaries of computer-assisted total knee replacement. J. Bone Joint Surg. Br. 87, 903-910

Young D. R., Kobluk C. N. (1995) Diseases of bone. In Kobluk C. N., Ames T. R., Geor I. J. (Eds): The Horse: Diseases and Clinical Management. Philadelphia, W. B. Saunders Company, St. Louis, Missouri, 785-786

Zusammenfassung

Vergleich der VetGate- und SurgiGATE 1.0-computerassistierten Chirurgiesysteme Systems zur Insertion von Zugschrauben über das Hufbein beim Pferd - eine In vitro-Studie

Mit einer experimentellen In vitro-Studie soll die Funktionalität und Präzision des VetGate Computer Assisted Surgery (CAS) Systems beim Implantieren von zwei $4.5 \mathrm{~mm}$ Kortexschrauben durch eine virtuelle, midsagittale Fraktur der distalen Phalanx 
(P3) beim Pferd und der Vergleich der Resultate mit denjenigen einer früheren, ähnlichen Studie mit dem SurgiGATE 1.0 CAS-System untersucht werden. Zur Verfügung standen fünf Gliedmaßenpaare $(\mathrm{n}=10)$ von Schlachtpferden, die frei von Pathologien in den Phalangen waren. Mittels zweier $4.5 \mathrm{~mm}$ Kortexschrauben und unter Überwachung sowie Mithilfe des VetGate CAS-Systems wurde eine virtuelle sagittale Hufbeinfraktur von der lateralen Seite fixiert. Es wurde darauf geachtet, dass weder das Hufgelenk, noch die Solaroberflächen penetriert wurden. Auch sollte der Semilunarkanal mit den Implantaten nicht beschädigt werden. Zuerst wird mittels eines C-Bogens, der während einer Minute um $190^{\circ}$ rund um den zu fixierenden Knochen bzw. Huf 100 Röntgenbilder aufnimmt und diese in 3 Schnittebenen widergibt, röntgenologisch untersucht. Diese Bilddaten werden anschließend auf das VetGate übertragen. Auf dem Bildschirm des VetGateSystems können die gewünschten Schraubenlokalisationen genau eingezeichnet werden. Anschließend hilft das Naviga- tionssystem des VetGate-Computers dem Chirurgen die Instrumente an die vorgeplante Lokalisation zu dirigieren und den chirurgischen Eingriff auszuführen. Alle Schrauben konnten auf diese Weise präzis implantiert werden, ohne eine der oben erwähnten Strukturen zu verletzen. Die Differenz zwischen den vorgeplanten und den effektiven Schraubenlängen ist mit dem VetGate CAS-System signifikant kleiner als mit derjenigen, die mit dem SurgiGATE 1.0 CAS-System erzielt wurde. Die Resultate, die mit dem VetGate CAS-System erzielt wurden, sind noch präziser als diejenigen des SurgiGATE 1.0 CAS-Systems $(p<0.001)$. Das VetGate CAS-System erlaubt das exakte Einsetzen von Schrauben in delikaten Lokalisationen unter Vermeidung von Verletzungen vitaler benachbarter Strukturen.

Schlüsselwörter - Computer-assistierte Chirurgie, Hufbeinfraktur, Osteosynthese, Schraubenplatzierung, passiv, optisches Zielgerät 